\title{
PROJETOS FERROVIÁRIOS EM SANTA CATARINA: AS TENTATIVAS FRACASSADAS PARA FORMAR UM SISTEMA FERROVIÁRIO CATARINENSE ${ }^{1}$
}

\author{
Alcides Goularti Filho²
}

\begin{abstract}
Resumo
O objetivo deste artigo é descrever e analisar os projetos ferroviários não executados em Santa Catarina apresentados entre os anos de 1867 a 1923. O texto está dividido em cinco partes. Inicialmente, faremos uma breve introdução sobre a primeira tentativa de implementação de uma ferrovia em Santa Catarina nos terrenos carboníferos em Laguna. Em seguida, apresentaremos as concessões estaduais da Estrada de Ferro Nova Capital ao Litoral - 1895, Estrada de Ferro São Francisco a Estreito - 1895, Estrada de Ferro Brusque a Itajaí - 1895, Ferrovia de Florianópolis - 1896, Estrada de Ferro São Francisco a Jaraguá - 1896, Estrada de Ferro Porto Belo ao Planalto Serrano - 1898, Estrada de Ferro Blumenau ao Rio Negro - 1898 e Estrada de Ferro Porto Belo ao Rio Iguaçu - 1912. Em terceiro lugar, discutiremos com mais profundidade os seguintes projetos: Estrada de Ferro Dom Pedro I, Estrada de Ferro Estreito a Lages, Estrada de Ferro São Francisco-Assunção e a Estrada de Ferro Estreito-Chopim. Em seguida, será apresentado o projeto da integração da EFDTC com a EFSPRG, ligando o sul com o oeste. E por último, o projeto frustrado da Rede Catarinense de Viação Férrea de 1923, que integraria todo o Estado formando um sistema ferroviário catarinense.
\end{abstract}

Palavras-chave: projetos ferroviários; Santa Catarina; história econômica.

Classificação JEL: N76 - N96 - R11

Pesquisa financiada pelo CNPq e FAPESC

Professor da Universidade do Extremo Sul Catarinense - UNESC. Doutor em Economia pelo IE/Unicamp 


\section{INTRODUÇÃO}

A primeira fonte documental em Santa Catarina sobre estrada de ferro é na Fala Provincial do Brigadeiro João Carlos Pardal, de 1839, que relata sobre a descoberta do carvão em Laguna. Segundo a Fala, junto às minas de carvão, suspeitava-se que também havia minas de ferro, o que facilitaria na "construção de uma estrada de ferro para a pronta condução do carvão aos lugares de embarque" (SANTA CATARINA, 1839, p. 12). A descoberta de carvão nos terrenos carboníferos de Laguna despertou o interesse de alguns capitalistas brasileiros que se dispuseram a explorá-lo. O primeiro a se manifestar foi o Visconde de Barbacena, que por meio do Decreto 2.737/1861, obteve a concessão para "lavrar as minas de carvão de pedra nas margens do Passo-Dois, distrito de Laguna" (BRASIL, 1861, p. 90). No contrato anexo ao decreto a cláusula terceira previa o seguinte:

\footnotetext{
Se for necessário fazer uma estrada de ferro para o transporte do carvão, poderá o Visconde de Barbacena desapropriar o terreno preciso para leito da mesma estrada e depósitos; não podendo, dentro de uma zona de cinco léguas para cada lado, construir-se outra estrada de ferro que siga direção paralela (BRASIL, 1861, p. 90).
}

Após onze pedidos de prorrogação do prazo, em 1874, o Decreto 5.744 concedeu a garantia de juros de 7\% para a construção da Estrada de Ferro Dona Tereza Cristina (EFDTC), também respaldada pela Lei Provincial 740 do mesmo ano. Finalmente, em dezembro de 1880, depois de 19 anos de espera, foram assentados os primeiros trilhos ligando as minas de carvão na cabeceira do Rio Tubarão aos portos de Laguna e Imbituba.

Durante a chamada "era ferroviária" brasileira, entre 1870 e 1930, foram apresentados inúmeros projetos ferroviários em Santa Catarina. Dado o caráter da sua estrutura econômica, na sua ampla maioria, estes projetos não foram executados. Até 1880, podemos afirmar que Santa Catarina era uma economia de subsistência e um território de passagem entre Rio Grande do Sul e São Paulo (GOULARTI FILHO, 2002). Neste período, a construção de ferrovias no Brasil se justificava caso houvesse um fluxo considerável de uma mercadoria destinada às exportações. No entanto, 
foram aprovadas várias concessões de privilégios e apresentados projetos regionais com o objetivo de integrar regiões não exportadora aos portos ou aos centros urbanos.

Havia no país vários complexos regionais autônomos pautados na economia agrária-mercantil-exportadora, como a borracha na Amazônia, o algodão no Maranhão, a cana-de-açúcar no Nordeste, o cacau no sul da Bahia, o café no Rio de Janeiro e São Paulo, a erva-mate no Paraná e o couro no Rio Grande do Sul. O sistema ferroviário estava condicionado a este padrão de acumulação agrário-mercantil-exportador, cuja integração do mercado interno fazia-se mais em função dos desdobramentos da acumulação dos complexos regionais, do que um projeto de Nação. A formação de uma rede ferroviária em São Paulo, Minas Gerais, Rio de Janeiro, Paraná e Rio Grande do Sul voltada para os principais portos se inserem neste padrão de acumulação.

A dinâmica da acumulação em Santa Catarina era muito lenta e pulverizada, além de apresentar uma fraca divisão territorial do trabalho. $\mathrm{O}$ litoral era colonizado por açorianos e predominava a pesca e o plantio da mandioca e da cana-de-açúcar, de onde eram extraídos a farinha, o melado e a aguardente e estava pautado na pequena propriedade. No planalto serrano predominava a pecuária extensiva, que se estendia para os campos de Palmas, e estava pautado na grande propriedade. A existência de núcleos coloniais era pontual e limitava-se a Blumenau, Brusque, Joinville, São Bento do Sul, Urussanga e Criciúma, além dos núcleos localizados próximo à região da Serra do Tabuleiro. Nas colônias predominava a pequena produção mercantil com a presença do sistema colônia-venda, onde eram produzidos e comercializados alimentos derivados de suínos, laticínios, cereais, pequenos utensílios e ferramentas, bebidas e têxteis. O sistema de transporte em cada região atendia as necessidades da produção da hinterland e permitia colocar a população local em contato com outras praças maiores.

Este quadro de lenta acumulação e isolamento regional inviabilizava a implantação de projetos ferroviários que integrassem Santa Catarina e permitisse dar um salto qualitativo na base produtiva. Somente nas regiões onde havia a lavra do carvão na cabeceira do Rio Tubarão, a extração da erva-mate no planalto norte e o corte da madeira no Vale do Rio do Peixe, todos destinados ao mercado externo, que viabilizou-se a construção de ferrovias em Santa Catarina. 
O objetivo deste texto é analisar os projetos ferroviários frustrados que pretendiam integrar o território catarinense do ponto de vista intra-regional e nacional. Daremos ênfase às concessões feitas pelo governo provincial e aos projetos ferroviários D. Pedro I, Estreito-Lages, Estreito-Chopim e São Francisco-Assunção, além das ligações entre a EFDTC e a Estrada de Ferro São Paulo-Rio Grande (EFSPRG). Por último, discutiremos o Plano Geral de Viação Férrea de Santa Catarina, apresentado por Joaquim José de Souza Breves Filho em 1923.

\section{AS CONCESSÕES ESTADUAIS}

Neste item serão apresentadas as diversas concessões feitas pelos governadores entre 1891 e 1912. Merece destaque as várias concessões feitas durante o governo de Hercílio Pedro Luz, de 1895 a 1898.

\subsection{Estrada de Ferro Nova Capital ao Litoral - 1895}

No início do primeiro governo Hercílio Luz (1895-1898) foi apresentada uma proposta para a construção de uma nova capital em Santa Catarina. A intenção era deslocar o centro administrativo do Estado para outra região afastada do litoral. Paralelo a esta iniciativa e como fator de estímulo ao projeto da nova capital, a Lei 169 de 30 de setembro de 1895 autorizou o governo do Estado a contratar com Pedro de Freitas Cardoso a construção de uma estrada de ferro e as edificações dos prédios da nova capital.

Com garantia de juros de $6 \%$ sobre quinze contos de réis por quilômetros, a estrada de ferro deveria ser de bitola estreita e ligaria a nova capital com um dos portos do litoral. Também foi concedido o privilégio da zona de vinte quilômetros de cada eixo da ferrovia. Os prazos para entrega do projeto eram de dois anos e um ano para aprovar a planta. Caso fosse executado o projeto da Estrada de Ferro Estreito-Chopim, a concessão para a construção da ferrovia perderia seu efeito (SANTA CATARINA, 1897).

Dois anos após a promulgação da lei, no dia 11 de outubro de 1897, foi editada a Lei 293, que concedeu a Pedro de Freitas Cardoso o privilégio apenas para construir uma estrada de ferro ligando a nova capital ao litoral. Ou seja, foram supridos os privilégios para a construção da nova capital, 
limitando-se apenas à ferrovia (SANTA CATARINA, 1897). Em 1904, por meio da Lei 227 de 5 de outubro, o contrato com Cardoso foi rescindido por não cumprir os prazos (SANTA CATARINA, 1910).

\subsection{Estrada de Ferro São Francisco a Estreito - 1895}

Houve várias tentativas de ligar as colônias de Blumenau e Joinville com a capital do Estado e com os portos de São Francisco e Itajaí, com foi o caso da Estrada de Ferro Estreito-Chopim, concedida pelo governo federal em 1890. Joinville comunicava-se com o porto de São Francisco do Sul por meio da navegação fluvial pelo Rio Cachoeira e Blumenau escoava suas mercadorias no porto de Itajaí também por meio da navegação fluvial pelo Rio Itajaí-açú. Porém, ambas as colônias não mantinham contato entre si, nem com a capital do Estado. A navegação marítima a vapor, feita por companhias nacionais, integrava as cidades portuárias catarinenses, mas a integração com o interior ainda era muito precária.

A construção de uma ferrovia entre os principais núcleos populacionais do Estado resolveria parcialmente os problemas da dificuldade de acesso entre o litoral com interior, além de contribuir para a fixação dos colonos.

A Lei 179 de 8 de outubro de 1895, um ano após ser declara caduca a concessão federal para a Estrada de Ferro Estreito-Chopim, o governo estadual concedeu a Carlos Fabris, o privilégio por 30 anos para construir uma ferrovia que partisse de São Francisco, passasse por Joinville, descesse até Blumenau e terminasse no Estreito. Frabis também tinha o direito de explorar vinte quilômetros de cada lado da linha. O projeto nunca foi executado e aos poucos a proposta foi sendo adaptada em novas concessões até resultar na Estrada de Ferro Santa Catarina (EFSC) em Blumenau.

\subsection{Estrada de Ferro Brusque a Itajaí - 1895}

A Lei 193 de 14 de outubro de 1895, autorizou o governo a contratar quem interessasse para construir uma estrada de ferro de bitola estreita ligando as cidades de Brusque a Itajaí. O privilégio seria por 60 anos com garantia de juros de $6 \%$ ao ano sobre um capital empregado de quinze contos de réis por quilômetro. Poderiam ser utilizados os leitos das estradas de 
rodagem para assentar os trilhos. Para esta concessão não houve interessados e não foi expedida nenhuma nova lei.

\subsection{Ferrovia de Florianópolis - 1896}

A Lei 209 de 29 de agosto de 1896 concedeu a Feliciano Marques ou à companhia que ele viesse a organizar o privilégio por setenta anos para construir uma ferrovia de bitola estreita que deveria partir do centro de Florianópolis, desse a volta na ilha e terminasse no Estreito. Também estava concedida para exploração a zona de quatro quilômetros para cada lado da estrada. Os trilhos poderiam ser assentados sobre as estradas de rodagem existentes, desde que não impedissem a passagem sobre os trilhos.

Marques também tinha a concessão para construir um "balneário" próximo das dunas, além da ponte da Lagoa da Conceição, ou em outro ponto mais conveniente do litoral da ilha (SANTA CATARINA, 1897).

\subsection{Estrada de Ferro São Francisco a Jaraguá - 1896}

No mesmo intuito da Lei 209, no dia 13 de outubro de 1896, foi editada a Lei 240, que concedeu a José Courau, o direito de construir uma ferrovia partindo da Lagoa de Saguassu (São Francisco), passando por Joinville, terminando em Jaraguá. Courau também tinha a preferência para construir dois prolongamentos: um até a cidade de Blumenau e outro até São Bento do Sul.

A garantia de juros era de $6 \%$ ao ano, num prazo máximo de trinta anos, para um capital de trinta contos de réis por quilômetros. Além disso, Courau tinha a concessão para explorar vinte quilômetros das terras de cada lado da ferrovia (SANTA CATARINA, 1897).

\subsection{Estrada de Ferro Porto Belo ao Planalto Serrano - 1898}

A Lei 322 de 20 de setembro de 1898 concedeu à Hyppolito Boiteux o privilégio por noventa anos para construir de uma estrada de ferro de bitola estreita partindo da cidade de Porto Belo, passando por Tijucas e Nova Trento, terminando na região serrana. A garantida de juros, o uso dos leitos das estradas e a concessão de terras eram as mesmas das demais leis de concessão. Na mesma lei foi concedido o direito de preferência 
para construir de prolongamentos até as cidades de Brusque e Blumenau (SANTA CATARINA, 1899).

\subsection{Estrada de Ferro Blumenau a Rio Negro - 1898}

A Lei 354 de 7 de outubro de 1898 concedeu o privilégio de noventa anos para A. W. Sellin construir uma ferrovia partindo de Aquidaban, no município de Blumenau, atravessasse o Rio Itajaí-Açú e o Vale do Rio Itajaí do Norte em direção ao Rio Negro, nas proximidades de onde hoje se situa a cidade de Canoinhas. Sellin também tinha preferência para construir um prolongamento até a cidade de Porto União.

Com em todas as concessões, a garantia de juros era de $6 \%$, sobre um capital de trinta contos de réis por quilômetro com direito a explorar vinte quilômetros de cada lado da ferrovia. Poderiam ser exploradas as terras para colonização, a madeira e os minerais encontrados na zona percorrida pela ferrovia (SANTA CATARINA, 1899).

Em 1904, foi editada a Lei 225 de 26 de setembro de 1904, que transferiu a concessão para Harry H. von Skinner. Mais tarde foi também concedido o privilégio para estender os trilhos até a EFSPRG e um ramal para Brusque. Desse projeto veio a ser concretizado apenas o trecho entre Blumenau e Hansa, com 69,7 quilômetros, denominada Estrada de Ferro Santa Catarina (SANTA CATARINA, 1910).

\subsection{Estrada de Ferro Porto Belo ao Rio Iguaçu - 1912}

A Lei 913 de 31 de agosto de 1912 concedeu à Companhia Paulista de Madeira o privilégio para construir uma estrada de ferro, partindo de Porto Belo, margeando o Rio Tijucas, dirigindo-se a Nova Trento, acompanhando o Alto Braço do Rio Tijucas, em direção ao núcleo Esteves Júnior. Daí a ferrovia seguiria para oeste em direção ao estado do Paraná até a confluência dos rios Chopim e Iguaçu (SANTA CATARINA, 1912)

\subsection{Concessões para Estrada de Ferro Dona Tereza Cristina}

Além destas concessões também foram autorizada a construção dos seguintes trechos ferroviários ligados a EFDTC: 
- Estrada de Ferro Tubarão a Araranguá concedida a Antonio Luiz Collaço e José Arthur Boiteux (Lei 110 de 5 de setembro de 1891).

- Trecho ferroviário entre Tubarão e Araranguá (Lei 121 de 5 de outubro de 1895) para João Luiz Collaço, ligando com a EFDTC.

- Extensão de um ramal da EFDTC de Imbituba ao porto de Maciambú, no litoral sul de Florianópolis, cedida a Feliciano Marques (Lei 229 de 23 de setembro de 1896).

- Construção de um ramal da Estrada de Ferro Dona Tereza Cristina, passando por Azambuja e Criciúma, terminando em Araranguá (Lei 452 de 26 de setembro de 1900).

\section{PRINCIPAIS PROJETOS FERROVIÁRIOS}

Neste tópico destacaremos os principais projetos ferroviários catarinenses que foram apresentados ao governo: Estrada de Ferro Dom Pedro I, Estrada de Ferro Estreito a Lages, Estrada de Ferro São Francisco-Assunção e Estrada de Ferro Estreito-Chopim.

\subsection{Estrada de Ferro Dom Pedro I 1867-1886}

O projeto para a construção de uma estrada de ferro que ligasse os futuros portos carvoeiros em Santa Catarina à cidade de Porto Alegre foi apresentado ao governo imperial por Sebastião Antônio Rodrigues Braga, em 1869. A proposta de Braga sucedeu a elaborada anteriormente, em 1867, por José Dias da Cruz Lima, que previa a construção de uma ferrovia ligando "a pitoresca província de Santa Catarina" ao centro da "rica província de São Pedro do Sul", cujo pedido de privilégio não foi aprovado. A estrada denominaria-se D. Izabel (LIMA, 1867).

O sistema de comunicação entre as duas províncias era muito precário, além de ser prejudicado pelas dificuldades de entrada nas barras de Laguna, Araranguá, Torres e Rio Grande. A comunicação entre Desterro e Porto Alegre era feita somente por via marítima, não existia a navegação fluvial, apesar da boa disponibilidade de rios e lagoas. As estradas existentes eram picadas abertas pelos tropeiros que chegavam até Conventos e Laguna. Entre as duas capitais havia uma vasta área para ser explorada e povoada. Com 
destaque para o "fértil" vale do Araranguá e os terrenos carboníferos na cabeceira do Rio Tubarão. O complexo lagunar da Lagoa dos Patos colocava Porto Alegre em contato com boa parte do litoral sul do Rio Grande do Sul, mas impedia de avançar mais ao norte em direção de Torres em função da falta de canais de navegação entre algumas lagoas.

Após um estudo sobre as vias de comunicação entre as duas capitais, Braga concluiu o seguinte:

Uma estrada de ferro de Santa Catarina a Porto alegre é a única alavanca poderosa que o Brasil faculta a essas províncias para de um golpe quebrar as algemas que apertam seus braços. Fizemos todos os estudos necessários para esse fim. (BRAGA, 1869, p. 18)

Por meio do Decreto 4.689 de 10 de fevereiro de 1871, Braga obteve a autorização para organizar uma companhia e construir uma estrada de ferro que deveria partir do melhor porto marítimo da província de Santa Catarina até Porto Alegre. No mesmo decreto ficou definido que a ferrovia denominar-se-ia D. Pedro I. Em setembro no ano seguinte, Braga organizou em Londres o capital necessário para formar a D. Pedro I Railway Company Limited, que foi autorizada a funcionar no Império no ano seguinte.

Após a autorização para funcionar, Braga enfrentou uma série de dificuldades para obter a garantia de juros e para alterar os prazos de entrega dos projetos. As maiores dificuldades foram enfrentadas junto ao governo provincial gaúcho, que entravava o andamento dos pedidos necessários para iniciar a elaboração do projeto (BRASIL, 1875 e 1877). Além da disputa com o Visconde de Barbacena, que já tinha obtido a autorização para construir a Estrada de Ferro Dona Tereza Cristina em 1874. Para amenizar os conflitos com Barbacena, chegou a ser proposto por Braga a fusão das duas ferrovias. (SOUZA, 1987).

Após uma hercúlea batalha junto ao Ministério, finalmente o Decreto 8.842 de 13 de janeiro de 1883 deu a garantia de juros de 6\% ao ano sobre um capital que não excedesse a $£ 4.000 .000$. No mesmo decreto ficou determinado que o prazo para início dos trabalhos preliminares seria de apenas 12 meses. No dia 19 de dezembro de 1883 foi dado início aos trabalhos de estudos da ferrovia na cidade de São José, em Santa Catarina. 
Ao contrário do governo gaúcho, o catarinense considerava a D. Pedro I "um acontecimento notável” para Santa Catarina.

Eu sinto-me lisonjeado pela fortuna de ver durante os dias da minha administração, realizada uma idéia que, executada, será um melhoramento real e fecundo para a província (SANTA CATARINA, 1883, p. 6)

Entre as cidades de Laguna e Porto Alegre, desde meados do século XIX também estava previsto construir um canal de navegação ligando os diversos rios e lagoas para integrar as duas cidades mais importantes do Brasil meridional. Em 1879, Eduardo José de Moraes apresentou um projeto detalhado sobre a viabilidade técnica e econômica de um canal de navegação. Moraes argumentava que o canal seria mais eficiente do que a ferrovia, que correria paralela ao canal (MORAES, 1879). É bom lembrar que no mesmo período no sul de Santa Catarina, também estava previsto a construção de uma ferrovia ligando as regiões das minas aos portos de Laguna e Imbituba.

No início de 1885, foi formada uma comissão fiscal para avaliar os estudos da D. Pedro I, que não estava cumprindo os prazos definidos. No relatório enviado ao Ministério, o engenheiro Firmo José de Mello concluiu que se fosse construir a ferrovia como estava previsto seria "um desastre para o nosso país" (BRASIL, 1885, p. 305). Com base no relatório e nas deficiências técnicas do projeto, o Decreto 9.689 de 24 de dezembro de 1886 não aprovou os estudos apresentados ao Ministério e declarou caduca a concessão.

Braga entrou com um pedido junto ao governo para que fosse indenizado pelos recursos já investidos no projeto, que foi negado pelo governo Imperial. Somente com o novo governo republicano que Braga foi indenizado, sepultando por definitivo o projeto da D. Pedro I.

\subsection{Estrada de Ferro Estreito a Lages 1888-1914}

Em 1888, a Lei Provincial 1.248, de 26 de outubro, autorizou o Presidente da província a conceder o privilégio por sessenta anos para quem oferecesse as melhores condições para construir uma estrada de ferro, que partisse do ancoradouro da baía da capital ou do município de São José até a cidade de Lages, no planalto serrano. O privilégio também era estendido 
à zona de quinze quilômetros de cada lado do eixo da estrada, excluindo o ponto de partida. A ferrovia deveria ser entregue num prazo máximo de dez anos e o concessionário era obrigado a depositar nos cofres provinciais a quantia de 10:000\$000 em dinheiro ou apólices com forma de caução (SANTA CATARINA, 1888).

Nessa época, a ligação entre o planalto serrano e o litoral era feita pelos caminhos desenhados pelos tropeiros. A transposição da Serra Geral tornava as viagens entre as duas cidades muito lentas. Como não havia um fluxo considerável de mercadorias e pessoas entre as duas regiões, o projeto nunca foi executado. Em função do fluxo de imigrantes - que estava se concentrando apenas no Vale do Itajaí, no planalto norte e no sul - seria estratégico também para o Estado levar os núcleos coloniais para o planalto serrano, que era "parcamente povoado". Além do mais, a ferrovia cortaria as colônias que estavam localizadas mais próximas da capital e que passavam por dificuldades.

Em 1895, no bojo das várias concessões realizadas, a Lei 211 de 3 de setembro concedeu a Feliciano Marques, ou à companhia que ele organizasse, o privilégio por noventa anos para construir uma estrada de ferro de bitola larga partindo de Florianópolis indo até Lages, terminando na divisa com o Rio Grande do Sul, no encontro com a EFSPRG. Deveriam ser construídos ramais para Painel, Capão Alto, Campo Belo, São Joaquim, Curitibanos e Campos Novos (SANTA CATARINA, 1896).

Em agosto de 1907, foi entregue ao Ministério da Indústria, Viação e Obras Públicas um requerimento pedindo a construção de uma estrada de ferro de Florianópolis à fronteira com a Argentina e ramais. A ferrovia partiria de Florianópolis, passaria por São José, Palhoça, seguindo até Lages, Curitibanos, Campos Novos, e dali partiria para a região de Palmas e Boa Vista, no oeste catarinense. De Palmas deveria partir um ramal até o vale do Chopim, atravessando o Rio Iguaçu, no Estado do Paraná. Para o sul, o ramal acompanharia o vale do Rio Chapecó até o Rio Uruguai. Do ponto mais conveniente entre Florianópolis e Lages, deveria seguir um ramal em direção à divisa com o Rio Grande do Sul, terminando onde fosse mais conveniente: no Rio Mampituba, no Rio Pelotas ou no Rio Uruguai (REQUERIMENTO, 1907).

Durante o governo Vidal José de Oliveira Ramos (1911-1914), ganhou força o projeto ferroviário Estreito a Lages. Vidal Ramos era de Lages e de- 
fendia os interesses dos pecuaristas que necessitavam de um novo estímulo, pois a pecuária estava num longo declínio desde o fim do tropeirismo e o enfraquecimento das feiras de Sorocaba.

No início do seu governo Vidal Ramos autorizou pela Lei 894 de 24 de agosto de 1911 a celebrar o acordo entre a casa bancária Louis Dreyfus \& Comp. de Paris e o Governo do Estado de Santa Catarina para construir e arrendar a Estrada de Ferro Estreito a Lages. O projeto era para que a ferrovia fosse eletrificada com bitola estreita com capacidade para 500 toneladas diárias. A garantia de juros era de 5\% ao ano para um capital investido de quinze contos de réis por quilômetro. Como era de praxe, também foram concedidos os terrenos ao longo da margem da ferrovia, a reserva de madeira, as pedreiras, as quedas de água para geração de energia, além dos leitos das estradas (SANTA CATARINA, 1911).

Para o governo estadual, esta ferrovia atendia o anseio de muitos, pois ligaria duas "importantes" regiões do território catarinense:

\begin{abstract}
A Estrada de Ferro Estreito-Lages irá servir uma vasta zona composta de seis futurosos municípios, com uma população superior a 100 mil almas, de um clima ameníssimo, solo fértil, de grande produtividade já notadamente na sua pujante indústria pecuária que abastece todo o Estado, exportando ainda para o Rio Grande do Sul e Paraná e nos cereais e frutos europeus (SANTA CATARINA, 1912, p. 66-67).
\end{abstract}

É bom lembrar que nesse período já havia ferrovias ligando os portos de Laguna e Imbituba às minas de carvão, entre Blumenau e Hansa, entre São Francisco e Corupá, e ferrovia cortando todo o meio-oeste no Vale do Rio do Peixe. Além dos projetos de expansão de Porto União a São Francisco e do prolongamento da Estrada de Ferro Santa Catarina até Itajaí. Faltava apenas ligar o litoral ao planalto serrano e transpor a barreira da Serra Geral.

No ano de 1913, por meio da Lei 716 de 7 de março, foi firmado o contrato com a casa bancária Louis Dreyfus \& Cia de Paris (SANTA CATARINA, 1916). Como o governo estadual não tinha os recursos suficientes para executar este projeto, a Lei Federal 2.728 de 04 de janeiro de 1913, que fixou as despesas da União, autorizou o governo federal a assumir a responsabilidade da metade dos ônus necessários para a construção da linha férrea. Porém, a Companhia Estrada de Ferro Santa Catarina (EFSC) 
apresentou ao governo federal um protesto contra a construção da ferrovia, pois a mesma zona que a Estreito-Lages iria atender, já estava previsto nos projetos iniciais da EFSC. Esta atitude da EFSC, uma empresa de capital externo, desagradou Vidal Ramos:

\footnotetext{
Estou, porém, convencido de que as absurdas pretensões da referida Companhia não lograram impedir que seja realizada uma das mais vivas aspirações do Estado, o que seria um tremendo golpe vibrado neste querido pedaço da pátria brasileira, cujo progresso depende principalmente da projetada via férrea. (SANTA CATARINA, p. 65-66, 1913)
}

Num relatório enviado ao governador Vidal Ramos em 1912, a Louis Dreyfus, argumentava que seria muito dispendioso para os cofres públicos seguir adiante com o projeto de eletrificação da ferrovia, uma vez que a queda da água disponíveis no trajeto era insuficiente para gerar a energia demandada pela via férrea (SANTA CATARINA, 1912).

Em função do governo federal não cumprir com a promessa de assumir metade do ônus previsto na lei, foi inviabilizado o começo das obras. O início da Primeira Guerra Mundial e a saída de Vidal Ramos do governo, sendo sucedido por Filippe Schmitd, que não demonstrou interesse pela ferrovia levou ao abandono do projeto da Estreito-Lages.

Com a incorporação do patrimônio da EFSC (que era de capital alemão) pelo governo federal em 1919 e seu repasse ao governo estadual em 1921, e com previsão de prolongar a linha para leste (Itajaí) e oeste (fronteira com a Argentina, passando pelo planalto serrano), do ponto de vista financeiro, seria quase que impossível o governo estadual manter duas ferrovias que concorreriam entre si. O projeto da Estreito-Lages foi abandonado e o governo estadual concentrou seus esforços na EFSC.

\subsection{Estrada de Ferro São Francisco-Assunção 1890-1917}

A tentativa de ligar o litoral sul-brasileiro até a fronteira do Paraguai remota ao Tratado de Aliança Defensiva assinado em Assunção no dia 25 de dezembro de 1850, quando ficou definido no Artigo XIII que seria aberto uma de estradas rápidas e seguras para estabelecer comunicações regulares entre as duas nações (BRASIL, 1852). 
Em 1890, o coronel engenheiro Dionício Cerqueira e Carlos Napoleão, o engenheiro civil Ricardo Longe, o capitão engenheiro João do Rego Barros e o capitalista João Marcílio Pereira Moraes apresentaram uma proposta ao Ministério da Agricultura para abrir uma estrada de ferro partindo do porto de São Francisco do Sul, seguindo até o povoado de Tucurupucú no Paraguai. Do porto de São Francisco do Sul também sairia um ramal até a colônia de Blumenau, partindo para o planalto serrano catarinense seguindo até o Rio Iguaçu (BRASIL, 1890b).

$\mathrm{Na}$ Exposição Financeira e Técnica apresentada pela Companhia Estrada de Ferro São Paulo-Rio Grande em 1900, foi reforçada a intenção de construir um ramal entre o Rio Iratí ao porto de São Francisco do Sul, que foi garantido no ano seguinte com a publicação do Decreto 3.947, que fez uma ampla revisão das concessões feitas à Companhia (COMPANHIA ESTRADA DE FERRO SÃO PAULO-RIO GRANDE, 1900).

A Companhia Estrada de Ferro S. Paulo-Rio Grande obrigou a celebrar os acordos necessários para fazer a ligação da Linha São Francisco à foz do Rio Iguaçu com as linhas do Paraguai no ponto que fosse mais conveniente, construindo um ramal e estabelecendo a ligação fluvial. Neste mesmo ano, a Brazil Railway Company incorporou uma estrada de ferro no Paraguai que possibilitaria integrar com a EFSPRG por meio de uma extensa linha entre São Francisco-Assunção.

No relatório da Secretaria de Negócios do Estado de 1915, apresentado ao governador, o secretário Fulvio Aducci argumentava que das quatro ferrovias existentes em Santa Catarina apenas a Linha São Francisco era a mais importante. A EFSC era tão-somente uma ferrovia municipal, a EFDTC ficou reduzida a uma linha secundária e quase inútil, a EFSPRG cortava uma região que estava sob jurisdição do Paraná, já a Linha São Francisco no futuro estaria integrada com o Mato Grosso, Paraguai e Bolívia, tornandose um "grande caminho" por onde passariam as mercadorias destinadas ao mercado norte-americano e europeu (SANTA CATARINA, 1915).

Como é de conhecimento, o único trecho construído do projeto São Francisco-Assunção foi entre São Francisco do Sul e Porto União. A construção foi feita em várias etapas, iniciada em 1906, entre São Francisco e Corupá, e concluída em 1917. 


\subsection{Estrada de Ferro Estreito-Chopim 1890-1894}

O projeto da Estrada de Ferro Estreito-Chopim teve vida efêmera e uma relação com o projeto da Estrada de Ferro São Francisco-Assunção. O Decreto 896 de 18 de outubro de 1890 concedeu o privilégio e a garantia de juros de 6\% ao ano para Dionísio Cerqueira, Carlos Napoleão Poeta e João do Rego Barros construírem uma ferrovia partindo do Estreito seguindo até o vale do Rio Iguaçu, em frente à foz do Rio Chopim, com ramais para o porto de São Francisco do Sul, Passo Fundo e Porto Alegre.

Em seguida foi constituída a Companhia Estreito e São Francisco ao Chopim, que foi autorizada a ser transferida para outros proprietários. Como não houve o cumprimento das cláusulas do contrato, o Decreto 1.853 de 22 de outubro de 1894 declarou caduca a concessão.

\section{INTEGRAÇÃO DA EFDTC COM A EFSPRG 1910-1918}

Quando a EFDTC foi incorporada pela EFSPRG, que pertencia à BRC, por meio do Decreto 7.928 de 31 de março de 1910, ficou determinado que a Tereza Cristina deveria expandir suas linhas até o encontro com a EFSPRG e a Linha São Francisco. A expansão até São Francisco atenderia as necessidades de construir um novo porto carvoeiro na enseada de Maciambú, no litoral sul de Florianópolis. O prazo era de dois anos para integrar com a Linha São Francisco e cinco com a EFSPRG. Em direção ao sul a Tereza Cristina deveria encontrar-se com a Viação Férrea Rio Grande do Sul, que era o antigo projeto da D. Pedro I.

A integração da EFDTC com as demais ferrovias formaria um sistema ferroviário catarinense e unificaria todos os portos com o interior, permitindo um maior fluxo de pessoas e mercadorias dentro do território catarinense. Com a transferência da EFDTC para a Companhia Brasileira Carbonífera de Araranguá (CBCA), em 1918, o projeto foi abandonado, concentrando-se a CBCA apenas na construção de novos trechos ferroviários na própria região carbonífera. 


\section{PROJETO DA REDE CATARINENSE DE VIAÇÃO FÉRREA}

A Lei 230 de 23 de setembro de 1903 concedeu a Henrique Schüler o direito para construir uma estrada de ferro denominada Norte-Sul e outra Leste-Oeste, ou seja, cortando todo território catarinense. A concessão foi declarada caduca em 1906. Esta foi a primeira tentativa para formar uma rede ferroviária integrada em Santa Catarina.

No ano de 1923, Joaquim José de Souza Breves Filho, diretor da Estrada de Ferro Santa Catarina, apresentou ao governo estadual um projeto para formação de uma rede ferroviária catarinense. A intenção era integrar a EFSC com a EFDTC, EFSPRG e a Linha São Francisco, integrando todos os portos com o interior. Breves Filho também chamava a atenção para uma futura integração com a Estrada de Ferro Rio Negro a Caxias, que cortaria todo o planalto serrano catarinense.

\footnotetext{
São patentes as vantagens que adviriam da formação dessa importante rede de viação, de cerca de 2.000 quilômetros, que, embora interessando mais especialmente ao Estado de Santa Catarina, concorreria extraordinariamente para completar o plano geral da viação do sul do país (ESTRADA DE FERRO SANTA CATARINA, 1923, p. 10)
}

O tronco principal desta rede seria a EFSC, que ligaria o litoral, porto de Itajaí, ao interior, cortando a Serra do Mar e a Serra Geral, chegando até a fronteira com a Argentina, passando pela Estrada de Ferro Rio Negro e pela EFSPR: “constituirá por certo o coletor principal do tráfego da rede delineada” (ESTRADA DE FERRO SANTA CATARINA, p. 11, 1923). Deste coletor principal partiria os seguintes ramais:

- Ligação de Blumenau ao Estreito

- Ligação de Blumenau à Linha São Francisco

- Ramal do Rio do Sul ao Estreito

- Prolongamento do ramal de Hansa até Nova Bremen.

Este ousado projeto seria realizado em conjunto com o governo federal, que faria mediante a realização de contratos de arrendamento e construção. 
O prazo previsto para a construção dos 1.200 quilômetros faltantes seria de 12 anos, com uma previsão de serem construídos 100 quilômetros por ano. Breves Filho admitia a possibilidade de dilatar o prazo, porém alertava que não poderia deixar de assegurar "a sua completa realização, gradualmente, sem soluções de continuidade" (ESTRADA DE FERRO SANTA CATARINA, 1923, p. 11)

No mesmo ano o governador Hercílio Luz apresentou o projeto de Breves Filho à Assembléia Legislativa na sua Mensagem anual. Luz, após reproduzir a proposta de integração ferroviária, concluiu que poderíamos denominar aquele projeto de "Rede Catarinense" (SANTA CATARINA, 1923).

\section{REFLEXÃO FINAL}

Talvez a pergunta que mais vem à tona após analisar inúmeros projetos ferroviários que não foram executados seria: por que eles não foram implementados? Se fôssemos pensar apenas do ponto de vista econômico a resposta seria simples: não havia fluxo suficiente de mercadorias que justificasse a implantação de uma ferrovia, ou seja, a acumulação era muito lenta. As únicas ferrovias que foram implantadas durante o período analisado foram a EFDTC, que transportava o carvão, a EFSPRG, que transportava a madeira e a Linha São Francisco, que transportava a madeira e a erva-mate. A EFSC era uma pequena ferrovia municipal que atendia pontualmente as colônias do Vale do Itajaí.

Uma ferrovia não se implanta com intenção de desenvolver uma região onde não há uma atividade econômica importante. Mas, pelo contrário, uma ferrovia é construída para atender uma região onde há uma grande atividade econômica que sustente financeiramente a ferrovia. É a circulação acelerando a produção. Esta era a realidade apenas para o carvão, a madeira e a erva-mate que estavam dentro do padrão de acumulação agrário-mercantil-exportador. A pequena produção mercantil era incapaz de sozinha manter os fluxos necessários para sustentar financeiramente uma ferrovia. 


\section{RAILWAY IN SANTA CATARINA STATE: FAILING ATTEMPTS TO BUILD UP A RAILWAY SYSTEM}

\section{Abstract}

The objective of this paper is to describe and analyze non-accomplished railway projects in Santa Catarina available during 1867-1923. The paper is divided in 5 sections. First, a brief introduction on the first attempt to implement a railroad in the coal-industry region of Laguna is made. Second, we describe the following railway projects: Nova Capital-Litoral (1895); São Francisco-Estreito (1895); Brusque-Itajaí (1895); Florianópolis (1896); São Francisco-Jaraguá (1896); Porto Belo- Planalto Serrano (1898); Blumenau-Rio Negro (1898); and Porto Belo-Rio Iguaçu (1912). Third, the following projects are discussed in more details: Dom Pedro I; Estreito-Lages; São Francisco-Assunção; and Estreito-Chopim. Fourth, the integration project linking EFDTC with EFSPRG, connecting the southern and the western egion of the state, is discussed. Lastly, we analyze the frustrated 1923 project of the State Railway Company of Santa Catarina to integrate the whole state into a railway system.

Keywords: Railway projects, Santa Catarina, Economic history.

\section{REFERÊNCIAS}

\section{a) Leis e decretos}

BRASIL. Coleção de leis do Império do Brasil de 1861. Rio de Janeiro: Tipografia Nacional, 1862. Disponível em <http://www.camara.gov.br> Acesso em 03 de maio de 2007.

Coleção de leis do Império do Brasil de 1871. Rio de Janeiro: Tipografia Nacional, 1872. Disponível em <http://www.camara.gov.br $>$ Acesso em 03 de maio de 2007. 
Coleção de leis do Império do Brasil de 1873. Rio de Janeiro: Tipografia Nacional, 1874. Disponível em <http://www.camara.gov.br $>$ Acesso em 03 de maio de 2007.

. Coleção de leis do Império do Brasil de 1874. Rio de Janeiro: Tipografia Nacional, 1875. Disponível em <http://www.camara.gov.br $>$ Acesso em 03 de maio de 2007.

Decreto $n^{0} 8.842$ de 13 de janeiro de 1883. Brasília: Senado Federal. Disponível em $<$ http://www.senado.gov.br $>$ Acesso em 08 de maio de 2007.

Decreto $\mathrm{n}^{\mathbf{0}} \mathbf{9 . 6 8 9}$ de 24 de dezembro de 1886 . Brasília: Senado Federal. Disponível em <http://www.senado.gov.br $>$ Acesso em 08 de maio de 2007.

Decreto $\mathrm{n}^{0} 10.185$ de 09 de fevereiro de 1889. Brasília: Senado Federal. Disponível em <http://www.senado.gov.br $>$ Acesso em 08 de maio de 2007.

Decreto $n^{0} 333$ de 12 de abril de 1890. Brasília: Senado Federal. Disponível em $<$ http://www.senado.gov.br $>$ Acesso em 08 de maio de 2007.

Decreto $n^{0} 452$ de 04 de junho de 1890. Brasília: Senado Federal. Disponível em $<$ http://www.senado.gov.br $>$ Acesso em 08 de maio de 2007.

Decreto n 3.947 de 07 de março de 1901. Brasília: Senado Federal. Disponível em $<$ http://www.senado.gov.br $>$ Acesso em 08 maio 2007.

Decreto $\mathbf{n}^{0} \mathbf{7 . 9 2 8}$ de 31 de março de 1910. Brasília: Senado Federal. Disponível em $<$ http://www.senado.gov.br $>$ Acesso em 08 maio 2007. 
Lei $n^{0} 3.141$ de 30 de outubro de 1882. Brasília: Senado Federal. Disponível em $<$ http://www.senado.gov.br $>$ Acesso em 08 de maio de 2007.

Lei $n^{0} 2.738$ de 04 de janeiro de 1913. Brasília: Senado Federal. Disponível em $<$ http://www.senado.gov.br $>$ Acesso em 08 de maio de 2007.

SANTA CATARINA. Leis e resoluções da Província de Santa Catarina 1888. Desterro: Tipografia do Conservador, 1888.

Coleção das leis do Estado de Santa Catarina promulgadas no ano de 1895. Joinville: Tipografia C. W. Boehm, 1897.

. Coleção das leis do Estado de Santa Catarina promulgadas no ano de 1896. Joinville: Tipografia C. W. Boehm, 1897.

Coleção das leis do Estado de Santa Catarina promulgadas no ano de 1897. Joinville: Tipografia C. W. Boehm, 1898.

. Coleção das leis do Estado de Santa Catarina promulgadas no ano de 1898. Joinville: Tipografia C. W. Boehm, 1899.

Coleção das leis do Estado de Santa Catarina promulgadas no ano de 1900. Joinville: Tipografia C. W. Boehm, 1901.

. Decretos e atos do poder executivo de 1904 a 1909 do Estado de Santa Catarina. Florianópolis: Tipografia do Dia, 1910.

Decretos e atos de 1910 a 1913 do Estado de Santa Catarina. Florianópolis: Tipografia do Dia, 1916.

Coleção de leis do Estado de Santa Catarina de 1912. Florianópolis: Tipografia do Dia, 1912. 
b) Relatórios

BRASIL. Relatório da Repartição dos Negócios Estrangeiros apresentado pelo Ministro Paulino José Soares de Souza à Assembléia Geral Legislativa. Rio de Janeiro: Universal de Laemment, 1852.

Relatório do Ministério dos Negócios, da Agricultura, Comércio e Obras Públicas apresentado à Assembléia Geral Legislativa pelo Ministro José Fernandes da Costa Pereira Júnior em 2 de maio de 1875. Rio de Janeiro: Tipografia Americana, 1875.

Relatório do Ministério dos Negócios, da Agricultura, Comércio e Obras Públicas apresentado à Assembléia Geral Legislativa pelo Ministro Thomaz José Coelho de Almeida. Rio de Janeiro: Tipografia Perseverança, 1877.

Relatório do Ministério da Agricultura, Comércio e Obras Públicas apresentado à Assembléia Geral Legislativa pelo Ministro João Pereira de Moura. Rio de Janeiro: Imprensa Nacional, 1885.

Relatório do Ministério da Agricultura, Comércio e Obras Públicas apresentado ao governo provisório pelo Ministro Francisco Glicério. Rio de Janeiro: Imprensa Nacional, 1890a.

junho de $1890 \mathrm{~b}$.

Requerimento - Documento avulso. Rio de Janeiro, 20 de

COMPANHIA ESTRADA DE FERRO SÃO PAULO-RIO GRANDE. Exposição financeira e técnica. Rio de Janeiro: Tipografia do Jornal do Comércio, 1900.

ESTRADA DE FERRO SANTA CATARINA. Relatório apresento ao governador pelo Diretor Joaquim José de Souza Breves Filho no ano de 1922. Blumenau, 1923. 
REQUERIMENTO. Pedido de construção de uma estrada de ferro de Florianópolis a fronteira Argentina e ramais. Rio de Janeiro, 24 de agosto de 1907.

SANTA CATARINA. Discurso pronunciado na abertura da Assembléia Legislativa pelo Presidente da Província João Carlos Pardal em 1839. Desterro, 1839. Disponível em $<$ http://www.crl.edu $>$ Acesso em 03 de maio de 2007.

. Relatório do Vice-Presidente Manoel Pinto Lemos da Província de Santa Catarina de 27 de janeiro de 1883. Desterro: Tipografia da Cidade, 1883.

. Mensagem do Governador Vidal José de Oliveira Ramos enviada ao Congresso Representativo em 23 de julho de 1911. Florianópolis: Tipografia do Dia, 1911.

. Mensagem do Governador Vidal José de Oliveira Ramos enviada ao Congresso Representativo em 23 de julho de 1912. Florianópolis: Tipografia do Dia, 1912.

. Mensagem do Governador Vidal José de Oliveira Ramos enviada ao Congresso Representativo em 24 de julho de 1913. Florianópolis: Tipografia do Dia, 1913.

Mensagem do Governador Hercílio Pedro Luz enviada ao Congresso Representativo em 22 de julho de 1923. Florianópolis, 1923.

Relatório da Secretaria Geral dos Negócios do Estado apresentado ao governador do Estado pelo Secretário Geral Caetano Vieira da Costa em 30 de junho de 1911. Florianópolis: Tipografia Livraria Moderna, 1911. 
Relatório da Secretaria Geral dos Negócios do Estado apresentado ao governador do Estado pelo Secretário Geral Gustavo Lebon Regis em maio de 1914. Florianópolis: Tipografia Livraria Central, 1914.

Relatório da Secretaria Geral dos Negócios do Estado apresentado ao governador do Estado pelo Secretário Fulvio Aducci em junho de 1915. Florianópolis: Tipografia do Dia, 1915.

c) Livros

BRAGA, Sebastião Antonio Rodrigues. Projeto de estabelecimento de uma estrada de ferro de Santa Catarina a Porto Alegre. Rio de Janeiro: Tipografia Americana, 1869.

GOULARTI FILHO, Alcides. Formação econômica de Santa Catarina. Florianópolis: Cidade Futura, 2002.

LIMA, José Dias da Cruz. A estrada de ferro da província de Santa Catharina a S. Pedro do Sul. Rio de Janeiro: Tipografia N. L. Vianna \& Filhos, 1867.

MORAES, Eduardo José. O canal de junção da Laguna a Porto Alegre. São Paulo: Tipografia de José Seckler, 1879.

RAMOS, Oscar de Oliveira. O problema ferroviário de Santa Catarina. Florianópolis: Tipografia do Dia, 1915.

SOUZA, Sara Regina Silveira. A D. Pedro I Railway: Sebastião Antonio Rodrigues Braga e a ferrovia Desterro-Rio Grande. São Paulo: João Scortecci Editor, 1987. 